\title{
L'HOMME L'Homme
}

$193 \mid 2010$

Claude Lévi-Strauss (1908-2009)

\section{Le mussem de Meknès. Le déclin d'une tradition spirituelle}

The mussem of Meknès: The Decline of a Spiritual Tradition

\section{Mehdi Nabti}

\section{(2) OpenEdition \\ 1 Journals}

Édition électronique

URL : http://journals.openedition.org/lhomme/24352

DOI : 10.4000//homme.24352

ISSN : 1953-8103

Éditeur

Éditions de l'EHESS

\section{Édition imprimée}

Date de publication : 19 février 2010

Pagination : 137-165

ISSN : 0439-4216

\section{Référence électronique}

Mehdi Nabti, « Le mussem de Meknès. Le déclin d'une tradition spirituelle », L'Homme [En ligne], 193 | 2010, mis en ligne le 29 janvier 2012, consulté le 10 décembre 2020. URL : http://

journals.openedition.org//homme/24352 ; DOI : https://doi.org/10.4000/lhomme.24352

\section{(c) École des hautes études en sciences sociales}




\title{
Le mussem de Meknès. Le déclin d'une tradition spirituelle
}

\author{
Editions de l'E.H.E.S.S. | L'Homme
}

\author{
$2010 / 1-n^{\circ} 193$ \\ pages 137 à 165 \\ ISSN 0439-4216
}

Article disponible en ligne à l'adresse:

http://www.cairn.info/revue-I-homme-2010-1-page-137.htm

Pour citer cet article :

"Le mussem de Meknès. Le déclin d'une tradition spirituelle", L'Homme, 2010/1 n 193, p. 137-165.

Distribution électronique Cairn.info pour Editions de l'E.H.E.S.S..

(C) Editions de l'E.H.E.S.S.. Tous droits réservés pour tous pays.

La reproduction ou représentation de cet article, notamment par photocopie, n'est autorisée que dans les limites des conditions générales d'utilisation du site ou, le cas échéant, des conditions générales de la licence souscrite par votre établissement. Toute autre reproduction ou représentation, en tout ou partie, sous quelque forme et de quelque manière que ce soit, est interdite sauf accord préalable et écrit de l'éditeur, en dehors des cas prévus par la législation en vigueur en France. II est précisé que son stockage dans une base de données est également interdit. 


\title{
Le mussem de Meknès \\ Le déclin d'une tradition spirituelle
}

\author{
Mehdi Nabti
}

$\mathrm{L}$

EUSSEM (terme vernaculaire dérivé de mawsim, litt. : "saison") de Meknès s'inscrit dans les festivités organisées au Maroc, à l'occasion de la célébration de la naissance du Prophète (al-mawlid al-nabawî). Il se déroule à la fois à l'intérieur et aux alentours de la zâwiya de la confrérie soufie des Aïssâwa, demeure qui abrite le tombeau du fondateur de l'ordre, Muhammad ben Aissâ, le Chaykh al-Kâmil (le "maître parfait »). À l'évocation des mussem-s, au Maroc, hommes, femmes, vieux ou jeunes, chacun voit les images d'une foule en liesse dans une ambiance surchauffée. Cependant tous n'y portent pas le même intérêt ni n'en donnent la même signification: la nature des mussem-s est complexe et ils sont plus ou moins importants pour les gens, selon l'âge, le sexe, la catégorie sociale et le lieu d'habitation. Il n'est donc pas aisé d'appréhender la signification de ce phénomène, profondément enraciné dans la société et la culture marocaine. Phénomène religieux, les mussem-s sont beaucoup plus que cela et manifestent une pratique collective d'un événement complexe, à la charnière du sacré et du profane, du récréatif et du méditatif, de l'urbain et du rural, du politique et du religieux.

Je propose d'apporter ici un éclairage sur le phénomène des pèlerinages maghrébins en tentant de dévoiler la signification et les enjeux de ce mussem dans la société marocaine contemporaine. Quel sens sa célébration revêt-elle pour le public pèlerin? Que révèle l'analyse des différentes formes de manifestations engendrées par cet événement ? Pour répondre à ces questions je commencerai par expliquer l'inscription des mussem-s dans les champs culturel et religieux en islam maghrébin. Je me consacrerai ensuite à l'étude du mussem de Meknès grâce à la description du site, l'analyse des pratiques rituelles des Aïssâwa et aux significations que le public 
pèlerin (disciples, commerçants et fidèles) confère au pèlerinage. En comparant mes données avec celles des travaux antérieurs sur le sujet, je conclurai sur le déclin actuel de cette tradition spirituelle.

\section{Qu'est-ce qu'un mussem ?}

Les mussem-s sont des fêtes saisonnières, à la fois foires et pèlerinages aux environs du sanctuaire d'un saint personnage (Reysoo 1991: 26). De part leurs aspects récréatifs, les mussem-s peuvent être rapprochés des foires médiévales et des kermesses européennes. Mais un rapport analogue de forme n'implique pas forcément une correspondance d'usage. La première question est de savoir comment il faut comprendre ces manifestations dans un contexte musulman. Le terme de haj (litt. : «se rendre à ") est employé uniquement pour désigner le pèlerinage canonique de La Mecque. Le mot mawsim, qui nomme les marchés saisonniers de l'Arabie ancienne, a évolué dans le double sens de saison et de fête, notamment à caractère religieux. Le terme a donné naissance au mot vernaculaire mussem qui qualifie les fêtes patronales maghrébines qui associent autour d'un sanctuaire des rituels religieux et mystiques, des foires et des fêtes foraines. Ces manifestations sont aussi appelées muled, dérivé dialectal du mot mawlid qui désigne la célébration de la naissance du Prophète. Si les pèlerinages de la chrétienté ont suscité une abondante littérature, en islam, la centralité du haj, le pèlerinage canonique à La Mecque, a longtemps dissimulé l'infinité et l'intensité des pèlerinages locaux. La littérature coloniale n'a pas produit de travaux spécifiques sur les pèlerinages musulmans bien que le phénomène confrérique et le culte des saints aient fait l'objet de toute son attention ${ }^{1}$. La plupart des travaux ultérieurs n'abordent le pèlerinage qu’à travers l'étude de la sainteté et des lieux saints, mais de nombreux chercheurs se penchent actuellement sur l'analyse des pèlerinages musulmans, à la fois au Maghreb (Chiffoleau \& Madouf 2005 ; Andezian 2001 ; Berriane 1992 ; Reysoo 1991 ; Crapanzano 2000) et au Proche-Orient (Madœuf 1997 ; Mayeur-Jaouen 2004).

\section{Les pèlerinages au Maghreb}

C'est principalement dans le cadre du culte des saints que s'inscrit la pratique du pèlerinage musulman, et cela en dépit du fait que la doctrine canonique de l'islam réfute la notion de sainteté. En ce qui concerne

1. Quelques exceptions cependant: cf. les écrits de Louis Massignon (1908, 1949) et ceux d'Edmond Doutté : "Notes sur l'islam maghrébin : les marabouts ", Revue d'histoire religieuse, 1900, 40 : 346-369 ; Revue d'histoire religieuse, $41: 22-66$ et 289-336; La Khot'ba burlesque de la fête des T'olba au Maroc, Paris, A. Colin, 1980 [1908] et enfin Magie et religion en Afrique du Nord, Paris, P. Geuthner, 1909. 
le Maghreb, les mussem-s, qui tirent leur origine de rites agraires (Reysoo 1991 : 28), sont aujourd'hui la conjugaison spécifique de culte des saints, de mysticisme et de foires périodiques. Malgré cette contradiction et ce caractère non orthodoxe, les chercheurs en sciences sociales qui mentionnent les mussem-s les classent parmi les fêtes religieuses, bien qu'ils ne figurent pas parmi les fêtes canoniques islamiques. Cette dénomination semble néanmoins convenir du fait qu'une grande partie des pratiques et des croyances qui entourent ces célébrations est orientée vers le divin. Le pèlerinage sur le tombeau d'un saint est une institution ancienne dans le pourtour méditerranéen. Les Bédouins, les Perses, les juifs comme les chrétiens effectuaient des pèlerinages sur le tombeau de leurs saints bien avant l'avènement de l'islam (Chiffoleau \& Madœuf 2005: 8), et la Kaaba de La Mecque, centre symbolique de la dévotion religieuse de l'islam, était déjà l'objet de vénération avant que le prophète Muhammad ne reçoive la Révélation. Avec l'avènement de l'islam, la triade pèlerinage-foire-fête populaire, déjà présente, se développera de multiples façons dans les régions conquises. Après la mort du Prophète, en plus de la Kaaba de La Mecque, la tombe de Muhammad à Médine attire les fidèles et une certaine vénération du prophète s'institutionnalise. Un de ses aspects en est la célébration publique de son anniversaire dès le XII ${ }^{e}$ siècle (Ibid. : 9). Les pèlerinages périodiques aux tombeaux de saints sont donc bien enracinés dans cette aire méditerranéenne. Bien qu'ils aient tous gardé un caractère cultuel, leur développement ultérieur en terre islamique a vu s’y ajouter divers éléments, notamment ceux issus du mysticisme. Vénérés de leur vivant et après leur mort, les saints locaux, humbles dévots ou illustres fondateurs d'une confrérie soufie, font l'objet d'une dévotion particulièrement intense au Maghreb, territoire géographiquement éloigné des trois lieux saints officiels de l'islam. Selon un hadîth, il n'existe que trois mosquées de pèlerinage en islam sunnite : La Mecque, Médine et Jérusalem² ${ }^{2}$. Les tombeaux des saints (qui deviennent souvent des zâwiya-s) démultiplient les lieux sacrés en passant outre à la liste canonique et en diffusant la baraka auprès des croyants. Trop souvent inaccessible pour le commun des fidèles, le pèlerinage canonique à La Mecque s'est vu remplacé dans la pratique par plusieurs pèlerinages secondaires auprès des tombeaux des saints, bien que dans l'esprit des participants et des pèlerins, le mussem ne se substitue pas au haj. Si ces deux pratiques n'ont pas le même sens, elles semblent remplir les mêmes fonctions. La "visite" (al-ziyâra) du saint, mort ou vivant, se justifie par la recherche de la baraka et la demande d'intercession auprès de

2. «Ne te rends qu’à ces trois mosquées, al-masjid al-harâm (La Mecque), al-masjid al-aqsâ (Jérusalem) et ma mosquée (Médine)». Cet hadîth, rapporté par Bukhârî et Muslim, sert d'argument aux opposants des sanctuaires des saints et à la visite des fidèles. 
Dieu. Cette démarche s'intègre dans des séquences rituelles qui comprennent des actes de purification, des processions, des prières, des retraites spirituelles, des offrandes, des sacrifices et des demandes que les fidèles adressent au divin par l'intermédiaire du saint. Quelle que soit l'importance des vœux, ce besoin de rencontre et d'intercession avec le divin où se manifestent aussi des aspects récréatifs et touristiques tisse dans l'aire panmaghrébine un immense réseau de pèlerinages. Ces manifestations mettent en jeu des pratiques complexes et variées, qui témoignent de la multiplicité d'approche et de vécu du fait religieux :

"Cette manifestation trouve donc son origine lointaine dans l'histoire des foires religieuses et de leurs aspects économiques et sociaux dans l'Arabie préislamique; mais aussi dans le mouvement maraboutique et la tradition des souks - deux phénomènes spécifiques au Maroc - et enfin, dans les rites agraires du monde berbéroméditerranéen. Elle offre le premier exemple, dans l'histoire socioculturelle du Maroc, d'une manifestation qui accorde une place de choix aux activités récréatives et aux distractions, et ce, malgré son caractère sacré. Elle s'accompagne en outre de déplacement de populations, qui convergent vers le même point, attirées par les nécessités du pèlerinage, mais aussi par le besoin de loisirs. Terminant le plus souvent l'année agricole, le moussem est enfin, le lieu de distraction du monde rural par excellence, le seul parfois» (Berriane 1993 : 29).

Les mussem-s, qui se superposent aux fêtes canoniques musulmanes, prennent place dans le calendrier lunaire et échappent à l'emprise des saisons. En dehors des jours de l' 'ä̈d («retour périodique»), il ne peut y avoir aucun jour sacré en islam ${ }^{3}$. En 1982, 753 mussem-s furent célébrés au Maroc (Ibid. : 30), tous en région rurale, à l'exception du mussem de Moulay Idriss à Fès et celui du Chaykh al-Kâmil à Meknès, tous deux situés en zone urbaine. Ce dernier a la particularité d'être célébré le jour du mawlid, la fête d'anniversaire du Prophète.

\section{La célébration du mawlid}

La célébration du mawlid («l'anniversaire du Prophète ») ${ }^{4}$ est l'un des faits religieux les plus contestés en islam car cette commémoration n'est pas une fête canonique. Sous la pression populaire et malgré la contestation de certains théologiens et juristes, sa célébration a fini par être acceptée comme "innovation bonne» (bid'a hasana) (Andezian 2001: 162). Actuellement, c'est un jour férié et certains ordres religieux comme les Aïssâwa organisent des processions au tombeau de leur saint fondateur.

3. Les fêtes canoniques sont l' 'aîd al-kabîr (la "grande fête ») appelée aussi 'aîd al-adhâ (la "fête du sacrifice»), célébrée en souvenir d'Abraham le 10 du dernier mois du calendrier hégirien, et l' 'aîd al-fitr (la "petite fête»), marquant la fin du mois du ramadan et l'arrêt du jeûne, le $1^{\text {er }}$ jour du dixième mois de l'année islamique.

4. Le mawlid ne commémore pas réellement la naissance du Prophète mais plutôt sa mort, car le jour de sa naissance n'est pas précisément connu. 
Le premier mawlid formellement et publiquement célébré eut lieu à Arbela, dans l'Égypte fâtimide, en 1207, le douzième du mois du troisième mois du calendrier musulman ( $\left.r a b \hat{\imath}^{\prime} I\right)$, où s'y déroulèrent des sacrifices d'animaux et des processions parmi lesquelles s'insérèrent des groupes de musiciens et des stands de divertissements (Ibn Khallikan [1256] cité in Reysoo 1991 : 4). Institué d'abord à Ceuta par le chaykh Abû al-Abbâs al'Azfi pour stopper les célébrations de la fête chrétienne de Noël par les musulmans, le mawlid fut officiellement introduit au Maroc par le sultan mérinide Abû Yảqûb Yûssef en 1292 et popularisé par les dynasties chérifiennes (Saâdide et Alawite) et par les ordres mystiques qui se revendiquaient une ascendance prophétique (Andezian 2001). La fête s'est répandue dans tout le Maghreb à partir du Maroc. Aujourd'hui les célébrations se déroulent dans les mosquées, dans les zâwiya-s, dans les maisons, dans la rue et jusqu'au plus haut sommet de l'État. Le jour du mawlid, les enfants sont rois et reçoivent des sucreries et des cadeaux. Les adultes et les personnes âgées participent aux cérémonies liturgiques, les visites aux zâwiya-s et la participation aux processions des confréries sont courantes.

En Algérie, sous la pression des réformistes (islâh) des années 1930, les cérémonies ne sont pas supprimées mais "épurées " de toutes les pratiques rattachées au soufisme, frein aux yeux des 'ulamầ à l'épanouissement de la foi ainsi qu'au sentiment d'appartenance nationale (Ibid.: 164). Les célébrations réformistes se caractérisent par l'abolition des rituels mystiques et par la mise à contribution active des écoliers aux rituels canoniques formels. Des modifications notables sont intervenues dans les célébrations des ordres mystiques: les offices liturgiques (poésies et dhikr) sont remplacés par des sermons et des enseignements à caractère éthique et religieux, liés à la personnalité du Prophète et à son œuvre (Ibid.). Le mawlid est l'occasion de réaffirmer son rôle dans l'histoire de l'humanité, sa biographie (al-sîra) est interprétée à travers des thèmes sociaux et éthiques. Les pratiques artistiques telles que la musique, la danse et les processions tiennent une place marginale et sont folklorisées par les autorités publiques. Outre les mosquées, les lieux de commémoration s'étendent aux écoles, aux théâtres, aux cinémas et aux places publiques. Ce mawlid réformiste, où toute expression de la spontanéité et de la gaîté est abolie, est adopté par les autorités officielles de l'Algérie indépendante. Actuellement la crise identitaire et économique que subit l'Algérie entraîne les membres des ordres mystiques à remettre en question la légalité des pratiques extatiques et culturelles locales sous la pression des islamistes. Bien que depuis quelques années existe un très officiel "festival aissaouas " à Mila, la religion étant devenue un enjeu de pouvoir, une mise en avant d'une "orthodoxie soufie " (si l'on peut dire) vise son inscription dans le champ de la légitimité religieuse. 
$\mathrm{Au}$ Maroc, le mawlid s'est toujours maintenu et il reste une fête très importante pour les confréries mystiques en activité (QâdiriyyaBûdchichiyya, Tijâniyya, Hamadcha et Aïssâwa, par exemple). De nombreux travaux scientifiques publiés et plusieurs thèses inédites en font référence. Les écrits de Vincent Crapanzano sur les Hamadcha (2000) et ceux de Viviana Pâques sur les Gnâwa $(1971,1991)$ mentionnent les pratiques mystiques qui de déroulent lors du mawlid. Actuellement et à cette occasion, les Aïssâwa organisent une cérémonie interne à la confrérie où sont conviés à la fois tous les muqaddem-s de Fès et de Meknès, les gestionnaires de la zâwiya-mère et les membres des familles respectives. Cette réunion, appelée "nuit du mawlid" (lîla al-mawlid) ou "nuit des muqaddem-s" (lîla al-muqaddmin), est programmée à l'initiative du muqaddem-muqaddmin qui en supporte financièrement la préparation, à savoir la location d'une salle (toujours dans un quartier chic de Fès et plus précisément sur la route d'Imouzer) pouvant accueillir plusieurs dizaines de sympathisants (et les membres de la famille des Aïssâwa), mais aussi l'embauche d'un traiteur qui se charge de préparer le repas collectif (couscous, thé, café et pâtisseries). Cette soirée se tient quelques jours après la fin du mussem du Chaykh al-Kâmil et a pour fonction, selon le témoignage du muqaddem-muqaddmin, de préserver le lien social entre les affiliés.

Hormis cette cérémonie privée, le mawlid est avant tout le moment, pour les Aïssâwa, de se rendre en pèlerinage sur le tombeau de leur saint fondateur. Les manifestations extérieures du mussem de Meknès ont été décrites au début du XXe siècle par René Brunel (1926: 130-143) et à la fin des années 1970 par André Boncourt (1980 : 270-294). Leurs écrits font aujourd'hui référence car ils ont été repris par les différents auteurs contemporains de langue française qui se sont consacrés à l'étude des Aïssâwa du Maroc dans des thèses non publiées (Elabar 2005; Saghir Janjar 1984) ${ }^{5}$. Les auteurs marocains qui se sont intéressés au sujet se sont surtout attachés à définir l'historique de l'événement et à le situer dans le champ religieux (Al Malhouni 2003 ; Daoui s. d. ; Aissawi Al-Chaykh AlKamil 2004). Dans son étude sur les Aïssâwa d'Algérie, Sossie Andezian pointe les processus de recréation rituelle dans un contexte de changement sociopolitique, à l'aide d'une comparaison de deux célébrations du mawlid par les Aïssâwa dans la région de Tlemcen en 1982 et en 1990. Cette approche comparative permet non seulement de rendre compte des modifications intervenues dans les célébrations mais aussi et surtout de mesurer les changements qui ont affecté la confrérie entre le début et la fin des années 1990. Son étude aboutit à une vision dynamique des rites

5. Seul Abdelati Lahlou nous offre une description du mussem de 1984. Ses données ne sont pas mises en relation avec les écrits antérieurs (1986: 240-251). 
qui évoluent à travers le temps, en mettant en évidence l'évolution des rapports que des individus, marginalisés dans le champ religieux et symbolique, entretiennent avec les institutions officielles (Andezian $2001: 165-185)$.

Mon analyse ne saurait prétendre à un examen aussi profond car les résultats de mon enquête de terrain sont plus limités dans le temps. Je n'ai pu me rendre au Maroc chaque fois que le mussem du Chaykh al-Kâmil était célébré mais j'ai cependant réussi à assister à ceux de mai 2003 et d'avril 2004 en tant que membre du public. Malheureusement ce dernier fut annulé pour cause d'intempéries. Ce sont les résultats de cette modeste enquête qui sont proposés ici.

\section{Le mussem à Meknès en 2003}

Le mussem du Chaykh al-Kâmil célébré l'année 2003 à Meknès tombe au même moment que la naissance du fils du roi Muhammad VI et de Lalla Salma Benani et se termine le jour où le pays subit les attentats islamistes de Casablanca. Le petit Moulay Hassan vient au monde le 8 mai, le mussem se tient les 14 (jour du mawlid), 15 et 16 mai, dates des attentats ${ }^{6}$. Le mussem du Chaykh al-Kâmil n'est donc pas endeuillé et est célébré dans la joie de la naissance du prince héritier. Toutes les places publiques des grandes villes sont mobilisées pour fêter la naissance du petit qui coïncide avec la période du mawlid. Presse, émissions télévisées et radiophoniques retransmettent les vœux de bonheur adressés à la famille royale. Depuis l'annonce publique de l'arrivée au monde du nourrisson, des photographies de la famille royale et des guirlandes ornent les édifices publics. Des orchestres folkloriques animent les rues de Fès et de Meknès, et les Aïssâwa en font partie. Le muqaddem-muqaddmin Haj Azedine Bettahi est chargé, par la préfecture, de la sélection d'une dizaine de tâ iffa-s qui ont l'obligation de se produire sur les plus grandes places des deux villes dans le cadre de concerts en plein air ou comme animation urbaine ponctuelle. Les vitrines des pâtisseries sont spécialement garnies et les rues connaissent l'affluence des jours de fête. Les enfants allument pétards et feux d'artifices, et, dès l'arrivée de la nuit, les mosquées et les zâwiya-s accueillent les fidèles. À Meknès, les commerçants

6. Le soir du 16 mai 2003, le Maroc est secoué par une vague d'attentats sans précédent. Par une série de cinq attaques quasi-simultanées dans la ville de Casablanca, le royaume est soudainement touché par le terrorisme international. L'opération, réalisée par 14 membres d'un groupe terroriste islamiste de mouvance salafiste, fait une quarantaine de morts et une centaine de blessés. Les objectifs visés étaient des institutions juives ou occidentales. Malgré un état d'alerte maximal, les mussem-s programmés après le 16 mai ne sont pas annulés. À propos de la situation actuelle, voir mon introduction (Nabti 2007). 
de la médina diffusent en boucle les musiques de la hadra des Aïssâwa. Des vendeurs de disques audio et vidéo projettent sur des écrans de télévision des films pirates filmés lors des précédents mussem-s du Chaykh al-Kâmil.

\section{En route pour la zâwiya-mère}

La veille de la célébration du mawlid et du début du mussem, je me rends à Meknès à la zâwiya-mère des Aïssâwa en passant par l'ancien marché aux bestiaux (souk larba') sur lequel sont installés une fête foraine, ainsi que le campement des disciples et pèlerins venus des régions rurales. L’origine géographique, l'appartenance ethnique, ainsi que la localisation de ces pèlerins sont des plus diversifiées, bien que beaucoup se présentent à moi comme des membres de la tribu des Saym Mokhtar du Rarb, du nom de la tribu qui accueillit, dit-on, le jeune Muhammad ben Aïssâ et son père. Nonobstant le fait que cette question nécessiterait une enquête plus approfondie, on peut affirmer que ces disciples, toutes obédiences confondues, sont recrutés au sein des classes défavorisées. Les activités professionnelles des pèlerins sont, d'après leurs témoignages, exercées dans le secteur primaire (ils peuvent être agriculteurs) ou dans celui des services (ils sont alors artisans). Les pèlerins ne sont jamais seuls, mais en famille, restreinte ou élargie, et habitent sous des grandes tentes berbères. Ils forment très souvent un groupe constitué par les représentants d'une tâ 'ifa, d'un quartier ou d'un village. Quelle que soit leur organisation, la mixité du groupe de disciples et des lieux de vie est de mise. Le campement est une véritable ville provisoire et attire différents types de commerces ambulants et informels. Outre les produits alimentaires de base (viande, fruits et légumes), les articles les plus représentés sont les confiseries, les rafraîchissements, les glaces, les ballons, les vêtements, les colliers, les cierges et les disques ${ }^{7}$ et cassettes des Aïssâwa (voir plan de la figure 1, p. 146). En m'approchant de la zâwiya, je remarque que celle-ci a retrouvé sa lumineuse couleur blanche. Chaque année et spécialement pour les festivités du mussem, l'extérieur est repeint à la chaux par les services municipaux. Sur l'esplanade flottent deux larges banderoles où figurent les inscriptions suivantes:

"Les churfa "fils du Chaykh al-Kâmil" félicitent sa majesté de la naissance du prince héritier son altesse royale le prince Moulay Hassan.»

"À l'occasion de la sainte fête du mawlid, les churfa "fils du Chaykh al-Kâmil" présentent à sa majesté le prince des croyants, son altesse le roi Muhammad VI les plus sincères félicitations et vœux de bonheur. "

7. Nous pouvons même trouver, pour 1 euro, des disques vidéo (VCD) pirates des anciens mussem-s filmés par des pèlerins. 
Des dizaines de véhicules des fidèles sont stationnés devant l'entrée. Certains sont immatriculés en Europe (Espagne, France, Belgique, Italie, Allemagne) et témoignent du rayonnement transnational de la confrérie. Le long des murs du cimetière qui entourent la demeure, les services municipaux installent des barrières de sécurité qui doivent contenir les mouvements de foule lors des cérémonies rituelles. Arrivé près de l'entrée, des jeunes femmes me proposent la réalisation d'un tatouage au henné (symbole de la baraka) tandis que des vendeurs de sucreries et de pâtisseries entrent et sortent de la zâwiya pour proposer leurs denrées aux visiteurs. Les disciples Aïssâwî venus du monde entier occupent l'intérieur du sanctuaire avec les pèlerins et les gestionnaires des lieux, descendants biologiques (me disent-ils) du fondateur de l'ordre religieux. Avant la prière canonique de l'aube (al-jafr) et pendant quarante jours avant le début du mussem, ils y récitent à voix haute des sourates du Coran, suivies de l'oraison de la confrérie, le hizb Subhân al-Dâ im (" gloire à l'Éternel "), puis de la wadhîfa rabbâniyya, des lectures du Dalâ il al-khayrât de Jazûlî, des poèmes issus de la Burda ${ }^{8}$ et des récitations de $d h i k r$-s. Moulay Idriss Aïssâwî, le responsable du sanctuaire, tient à m'expliquer les origines du mussem qu'il attribue à la seule volonté de son aïeul :

"C'est le Chaykh al-Kâmil lui-même qui a décidé de réunir tous ses élèves le jour de la naissance du prophète. Ils se réunissaient pendant sept jours dans la zâwiya pour une retraite spirituelle [al-khalwa, $n d r]$ dans l'amour du Prophète. Nous continuons ce qu'il a entamé. À l'époque les personnes présentes étaient les invités de la zâwiya, ils étaient entièrement pris en charge. Le but de leur présence était bien entendu la visite au chaykh pour bénéficier de sa baraka mais il n'y avait pas de programme spécial, mis à part la lecture du hizb à des heures précises à haute voix, comme aujourd'hui. Mais il n'y avait pas de tâ îfa-s avec des musiciens, juste des grands cortèges de disciples venus des campagnes en récitant le dhikr».

Quelques hauts responsables de la confrérie venus d'Algérie ou de Libye sont hébergés par les gestionnaires de la zâwiya-mère dans leur propre domicile. Pendant toute la durée de la célébration du mussem, la demeure offre le gîte aux pèlerins, hommes et femmes, venus des quatre coins du Maroc, du Maghreb et même d'Europe. Le mausolée de Sîdî Saïd (situé à environ deux kilomètres de la zâwiya), l'un des premiers disciples du shaykh, accueille lui aussi les fidèles. L'ambiance du lieu, d'ordinaire très calme, est particulièrement électrique : outre les pèlerins, la demeure doit supporter la visite de centaines de touristes ou curieux qui se pressent à l'intérieur. Tout le monde se retrouve à l'étroit et la tension monte rapidement entre les fidèles et les hôtes de passage. Les gestionnaires du lieu,

8. Al-Burda (litt. : «le manteau ») : ensemble de poèmes d'Al-Bûsîrî (XIII siècle) consacrés à l'éloge du Prophète. 
rapidement débordés par le flot incessant de visiteurs, sont aidés dans leur tâche par des gendarmes afin d'éviter tout type de débordement. La nuit qui précède le début du mussem, les forces de police et les gestionnaires évacuent presque entièrement la zâwiya, à l'exception des pèlerins qui n'ont pas d'autres alternatives de logement, car au petit matin le sanctuaire reçoit la visite des premiers disciples.

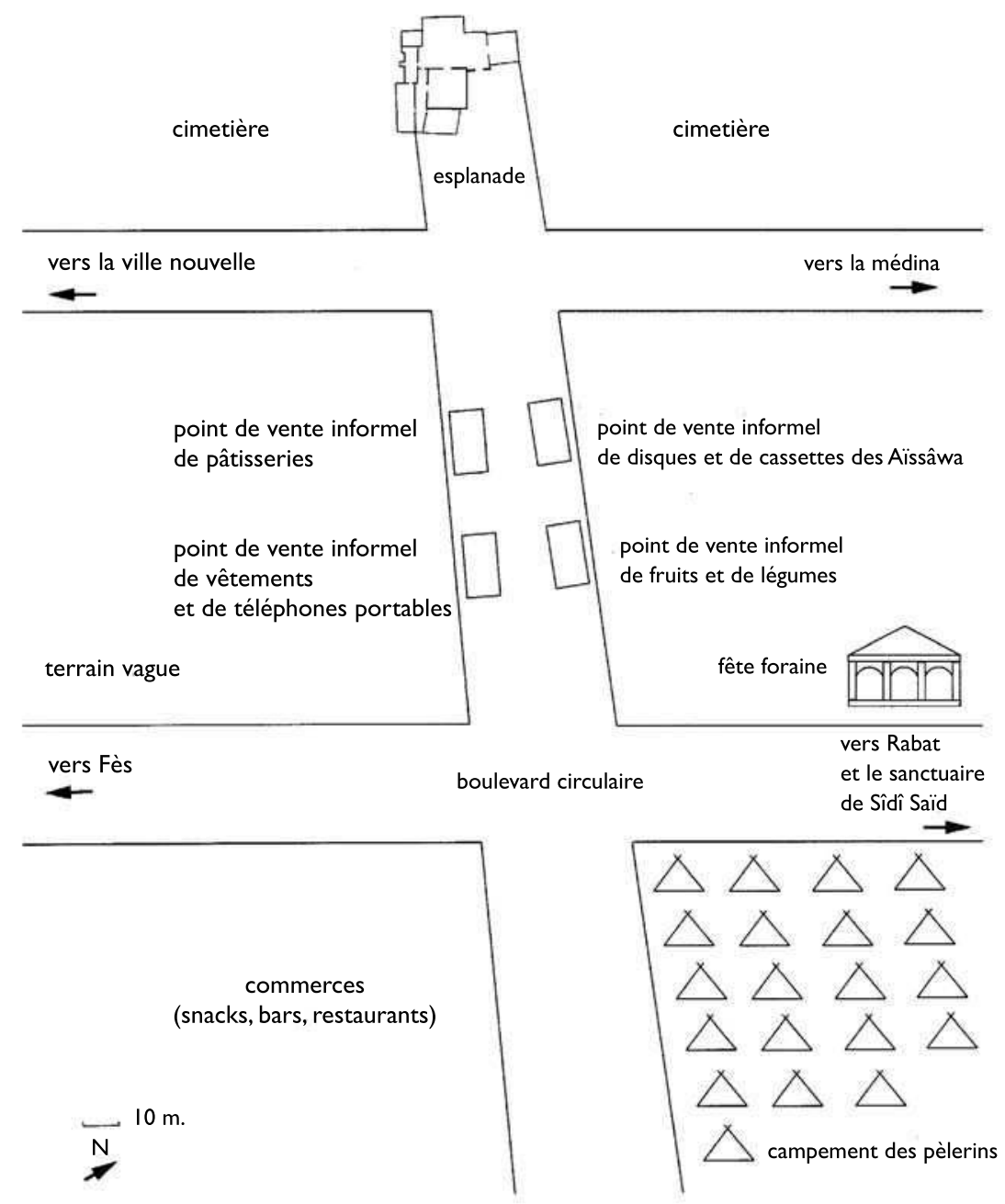

Fig. I Plan du mussem du Chaykh al-Kâmil ${ }^{9}$

9. Ce plan, réalisé par mes soins lors de mes enquêtes de terrain, se veut schématique et ne tient pas compte des normes du cadastre. 


\section{Description des processions}

Les processions des Aïssâwa se déroulent sur trois jours. Le premier jour est consacré aux défilés des tâ 'ifa-s venues des régions rurales et des membres de leur famille. Le deuxième est attribué aux $t \hat{a}$ if $a$-s des grandes villes du pays. Le troisième et dernier jour est exclusivement réservé à la tâ ifa du Palais royal, qui apporte les dons annuels matériels (al-hadiyya) et financiers (al-hîba) offerts au sanctuaire par le roi ${ }^{10}$. Interrogé sur cette organisation des défilés, Moulay Idriss Aïssâwî, le responsable de la zâwiya, affirme qu'il s'agit là d'un agencement d'ordre purement technique :

«Le premier jour est réservé aux Rarbâwî parce qu'ils sont très nombreux. Ils viennent de loin et c'est pour cela qu'ils doivent passer les premiers. Ils ont des pratiques particulières que les autres disciples ne font pas. Le deuxième jour nous recevons les tâ $i f a-s$ de Meknès, de Fès, de Salé, de Marrakech, de Tanger et de Tétouan. Le troisième jour est exclusivement réservé à la tâ ifa du Palais royal, elle clôt le mussem ".

Voici le déroulement des trois jours du mussem:

- La veille du premier jour, quelques groupes de disciples venus des régions rurales, des hommes et femmes (ces tâ 'ifa-s sont mixtes) qui campent depuis plusieurs jours dans le mausolée de Sîdî Saïd, récitent avec ferveur le hizb Subhân al-Dâ'im et différentes litanies mystiques. D'autres demeurent dans leur campement près de la zâwiya-mère et réalisent des hadra-s nocturnes. À $7 \mathrm{~h} 45$, un spectacle folklorique est donné par des cavaliers sur le parvis de la zâwiya qui exécutent une fantasia. À 8 h 30, des renforts des forces de l'ordre arrivent (cars de police, camions de l'armée, gendarmes) ainsi qu'une délégation officielle composée du gouverneur de la province de Meknès, du préfet, du commissaire et d'une dizaine de hauts fonctionnaires. Accueillis quelques instants par le mezwâr et certains membres de la "commission" (lajna) sur l'esplanade de la zâwiya, ils se dirigent ensuite sous une tente aménagée pour y suivre les festivités (voir plan fig. 4, p. 153). Les disciples arrivent rapidement par centaines en invoquant le nom de Dieu et en dansant la hadra. Répartis en plusieurs tâ if $a-s$, ils forment un immense cortège aligné le long du mur du cimetière qui entoure la zâwiya. Pour pouvoir assister au défilé, les spectateurs sont tenus de respecter des règles implicites : il ne faut pas être vêtu de rouge ou de noir. Les dévots, qui sont tous vêtus de blancs, peuvent avoir eux aussi des réactions imprévisibles lorsqu'ils sont en transe. Irrités par ces couleurs, ils ont pour habitude de se ruer sur les membres de l'assistance pour les agresser. Lors de mon enquête et peu avant le début du mussem, j'entamai la discussion avec une vieille femme membre d'une tâ ifa rurale à propos du déroulement des rituels. L'entretien a subitement été interrompu par le passage rapide d'un homme

10. À propos des rapports entre l'État et la zâwiya-mère des Aïssâwa, voir ma thèse (Nabti 2007). 
derrière moi qui portait un costume et un attaché-case de couleur noire, probablement en retard pour se rendre au travail. À sa vue, mon interlocutrice changea de comportement : elle m'abandonna subitement et se mit à crier et à courir dans sa direction, suivie par d'autres femmes de sa tâ 'ifa. Le malheureux eut tout juste le temps de s'engouffrer dans un taxi pour échapper à la furie de ses poursuivantes qui l'insultèrent copieusement. Peu après cet événement, la police et l'armée invitent le public qui arrive par grappe à se ranger derrière les barrières de sécurité. C'est de là que j’assiste au mussem, car l'accès à la zâwiya est maintenant interdit. Des dizaines de gendarmes sont disposés tout le long des barrières et jusqu’à l'entrée du sanctuaire. Un fonctionnaire est chargé de comptabiliser le nombre de tâ if $a$-s et de veiller à l'ordre de passage des groupes, celui-ci étant défini par la pose des étendards à la levée du jour : le premier groupe à installer ses drapeaux sur le mur du cimetière est le premier à visiter la zâwiya. À son signal, la première tâ ifa ouvre le mussem. Dans une course effrénée, les adeptes arrivent par dizaines, traversent l'esplanade et se jettent littéralement à l'intérieur de la zâwiya. Certains sont en transe et miment des personnagesanimaux. Leurs vêtements, d'un blanc immaculé, sont tachés de sang, ce qui me laisse supposer qu'ils se sont livrés au sacrifie de la frissa. On dit d'ailleurs que le premier groupe d'adeptes à pénétrer dans l'enceinte du sanctuaire doit obligatoirement être les sacrificateurs, les lions ( $\left.a l-s b a^{\prime}-s\right)$ et les lionnes (albiya-s), suivis ensuite des chameaux (al-jmâl-s). Cette séquence, appelée « la coutume» (al-'ada), accueillie par le public par de fortes clameurs et sous des applaudissements, représente un véritable spectacle. L'esplanade est entièrement occupée par les membres de la tâ 'ifa (qui sont des hommes et des femmes, ainsi que les membres de leurs familles) accompagnés de dizaines de sympathisants qui les ont rejoints peu avant leur arrivée sur l'esplanade. Certains disciples sont dans une transe violente, ils hurlent, pleurent et font mine de se battre en poussant des cris d'animaux. Dans certains cas extrêmes, il est fréquent que les femmes parlent, ou plutôt râlent, mais avec une voix qui n'est pas la leur : ce sont les jinn-s qui s'expriment à travers elles car elles sont, dit-on, possédées. À la vue des dévots en transe, certains vociferent des jurons tandis que d'autres souhaitent bénéficier de leur baraka: allant contre les recommandations des gendarmes, des jeunes femmes franchissent les barrières de sécurité et se couchent sur le parcours des disciples dans l'espoir d'être enjambées et piétinées. Les Aïssâwî en transe ont, parait-il, le pouvoir de pallier la stérilité et la paralysie des membres. En face de l'entrée de la zâwiya, quelques adeptes, souvent des vieilles femmes, s'arrêtent un instant et exécutent des figures animalières sous les clameurs du public. Quelques adolescents profitent de cet instant pour les insulter et leur jeter des pierres. Ils sont rapidement rappelés à l'ordre par 
les gendarmes qui leur somment, s'ils ne se modèrent pas, de quitter les lieux. Les musiciens sont le second groupe de disciples composant la tâ i ifa, jouant à l'aide d'idiophones (ta'rîja-s, tbel-s) et d'aérophones (hautbois reta-s) les thèmes musicaux de la hadra: le Rabbânî et le Mjerred ${ }^{11}$. Accompagné de dizaines de fidèles qui récitent le nom de Dieu (parfois en se frappant la poitrine), le cortège traverse l'esplanade en direction de la zâwiya et apporte un animal (généralement un mouton) qui sera sacrifié à l'intérieur du sanctuaire $^{12}$. Pendant l'avancée du cortège vers le lieu saint, c'est le Rabbânî qui est joué. À l'inverse, lors du Mjerred, qui est vu comme l'élévation spirituelle de l'âme et la visite du fidèle au Prophète, la tâ'ifa stationne devant l'entrée de la zâwiya et les croyants entament des danses rituelles. Juste avant de pénétrer dans le sanctuaire, les musiciens jouent à nouveau le Rabbânî, qui témoigne leur désir de retour sur terre et permet ainsi à la tâ i ifa de se déplacer. Certains danseurs sont pieds et tête nus (manifestation de leur saine intention, al-niyya), et, près de l'entrée de la sainte demeure, ils se mettent à genoux en arc de cercle et embrassent le sol pour, me dit-on, remercier Dieu. Une fois à l'intérieur, ils sont accueillis par les gestionnaires et sacrifient l'animal dans la cour intérieure pour l'emmener ensuite à l'abattoir et le dépecer. Ils restent quelques instants près du tombeau du Chaykh pour se recueillir avant de libérer l'endroit qui doit être visité par les autres tâ if $a$-s. Les forces de l'ordre chassent ceux qui traînent trop dans le mausolée, parfois à coups de matraque. Les processions se déroulent toute la matinée et se terminent vers 13 heures. En 2003, j’ai comptabilisé la présence de 17 tâ $i f a-s$ lors du premier jour du mussem.

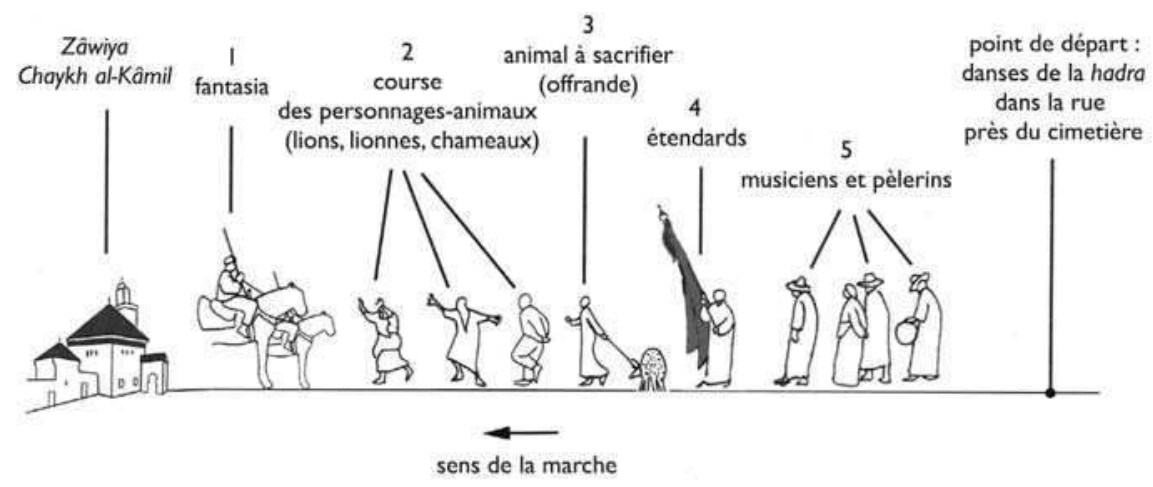

Fig. 2 Dessin de la visite des Aïssâwa le matin du ler jour

11. À propos du symbolisme de la hadra, voir ma thèse (Nabti 2007).

12. Pour une étude anthropologique et comparatiste sur la nature et la fonction du sacrifice en islam, tant à travers les textes canoniques que dans la diversité des pratiques quotidiennes (Maghreb, Turquie, France, Mauritanie), voir Bonte, Brisebarre \& Gokalp (1999). 
L'après-midi du premier jour la zâwiya est ouverte aux visiteurs qui se regroupent dans le tombeau du saint et dans la cour intérieure. S'élèvent alors des cantiques chantés par des disciples où la tristesse, la mélancolie, le souvenir des ancêtres, la mort, l'abandon et la famille sont les thèmes principaux. Ces psalmodies provoquent chez certains des pleurs et des hurlements d'extase. Parallèlement à ces actes de dévotion, des cassettes des oraisons mystiques enregistrées de façon informelle sont proposées à la vente par des fidèles qui circulent parmi le public. À cet instant, le mussem permet aux groupes ruraux de se réunir, d'exalter leurs valeurs et ainsi de se régénérer. Par le nombre de fidèles qui se retrouvent en ces moments de communion, le mussem ressoude les liens et abolit les différences sexuelles et sociales entre les croyants. En fin d'après-midi, les disciples quittent Meknès, leur campement se vide totalement.

- Toute la journée du deuxième jour du mussem, la zâwiya reste ouverte aux croyants en quête de la baraka du saint. Le nombre de visiteurs du sanctuaire est si élevé que les forces de l'ordre sont contraintes de réguler l'accès des lieux en refusant aux hommes d'y pénétrer. À l'inverse du premier jour, le défilé des Aïssâwa ne débute qu’à la nuit tombée. C'est le moment où les gendarmes évacuent entièrement la zâwiya: aidés par des dizaines de militaires, ils veillent en outre à ce que le public ne franchisse pas les barrières de sécurité. L'accès à la zâwiya est maintenant strictement interdit au public car le début du défilé est imminent.

Le muqaddem-muqaddmin Haj Bettahi m'explique, qu'auparavant, l'ordre de passage des groupes se décidait en début d'après-midi par le pointage des étendards dans le mausolée de Sîdî Saïd, point de départ du défilé situé à environ un kilomètre de la zâwiya. À l'heure actuelle, cet usage semble être abandonné, car tous les groupes Aïssâwa effectuent la visite au sanctuaire en démarrant des domiciles des particuliers. Vers 17 heures, les Aïssâwa ont rendez-vous pour célébrer une lîla («nuit») chez des clients habitants en médina de Meknès. Les Aïssâwa utilisent le matériel habituel (vêtements cérémoniels, accessoires rituels, instruments de musique) et suivent le déroulement standard de la cérémonie en trois parties (dhikr, mluk, hadra). Cependant, la troisième étape, la hadra, n'est pas effectuée entièrement à l'intérieur du domicile : pendant la danse du Rabbânî initial, les Aïssâwa (accompagnés de tous les membres de l'assistance) sortent du domicile pour la visite du sanctuaire. Le franchissement du seuil de la sphère privée pour investir la sphère publique est appelé simplement "la sortie", al-khaja. Il faut trois à quatre heures pour effectuer le parcours qui mène le cortège du domicile des clients jusqu'au sanctuaire du saint. La disposition de la tâ ifa se fait de la manière suivante : en tête nous trouvons les étendards (portés par les enfants de la famille 
invitant les Aïssâwa), suivis des dons matériels portés par les Aïssâwî, ensuite les danseurs (vêtus de la handira et pieds nus, signes de l'humilité du mystique), puis des musiciens percussionnistes (buznazen-s, tbel-s). Les joueurs de hautbois ferment la marche et sont juchés sur des mulets, suivis par les fidèles et les sympathisants, le public de la lîla. Lors du parcours, les musiciens jouent indéfiniment le Rabbânî et les danseurs effectuent un mouvement de balancier tout en répétant à voix haute "Dieu Éternel » (Allah Dâim). Le cortège sillonne les rues étroites de la médina de Meknès sous les applaudissements et encouragements des passants et des commerçants. Le muqaddem finance lui-même l'offrande matérielle (alhadiyya) apportée au sanctuaire par sa tâ ifa: il s'agit soit d'un animal à sacrifier (un bouf ou une vache, mais souvent l'animal est loué par les tâ ifa-s en manque d'argent et n'est pas sacrifié), soit de lustres, de tapis ou de tissus brodés (kaswa, litt. : "costume») pour décorer le mausolée du Chaykh al-Kâmil. Arrivé à environ une centaine de mètres de la zâwiya, le cortège est contraint de s'arrêter et de patienter derrière les autres tâ if $a_{a-s}$ qui se rendent aussi à la zâwiya. Débute alors une très longue pause qui permet aux musiciens de récupérer. Le public n'ayant pas le droit de pénétrer dans la zâwiya, des femmes laissent des foulards au muqaddem pour les récupérer après leur visite au sanctuaire. Faisant office de réceptacle de baraka, ces foulards bénis doivent permettre de lutter contre la stérilité. Un fonctionnaire vient ensuite prévenir le muqaddem que le mausolée est enfin accessible. Les Aïssâwa rejouent alors le Rabbânî et avancent jusqu'au centre de l'esplanade. Là, face au public et sur près d'une heure, ils exécutent la danse du Mjerred. Les danseurs, placés en arc de cercle, font face au muqaddem qui dirige la danse sereinement. À l'inverse des disciples présents le premier jour, la danse de transe reste ici très contrôlée. Seuls des cris extatiques surgissent: "Dieu»! (Allah) ou "L'envoyé de Dieu » (Rassûl Allah) sont les plus fréquents. Les musiciens sont à l'écart et jouent inlassablement les airs mélodiques. La tâ ifa occupe la moitié de l'esplanade, le reste est pris par la famille du foyer qui les accompagne (comprenons les femmes et leurs enfants, assistées de leurs maris ou frères) ainsi que quelques sympathisants qui les ont rejoints sur le parcours. C'est ici qu'a lieu le véritable spectacle et le public manifeste son enthousiasme par des cris et des applaudissements. Certaines femmes ont décidé de faire leur jedba, la danse d' "attirance ». Le geste introductif à la transe est souvent le dénouage des cheveux. La gestuelle la plus classique est le balancement de la tête d'avant en arrière, cheveux dénoués, ou de droite à gauche, avec un rythme saccadé qui s'accentue avec le crescendo de la musique. Ces cas de figure dénotent une jedba relativement calme. D'autres cas sont plus violents. Lorsque la transe a atteint son paroxysme, la femme peut se 
mettre à hurler, pleurer et se rouler au sol. Les gendarmes sont très présents sur les lieux et répriment brutalement les personnes qui tentent de franchir les barrières pour rejoindre les Aïssâwa. Pour reprendre la marche en direction du sanctuaire, le muqaddem fait signe à ses musiciens de jouer le Rabbânî final, thème qui leur permet de reprendre le défilé. Ce n'est que devant la porte d'entrée de la zâwiya qu'il indique à ses musiciens d'arrêter la musique. Les Aïssâwa et les fidèles qui les accompagnent se rendent jusqu'à l'intérieur du mausolée et y retrouvent les gestionnaires, à qui ils donnent leurs offrandes matérielles (tapis, lustres) et financières (un pourcentage sur les recettes annuelles de la tâ ${ }_{i f} f$ ). S’ils apportent un animal à sacrifier, celui-ci est immédiatement immolé dans la cour intérieure et emmené à l'abattoir pour y être dépecé. Après une prière collective effectuée dans le mausolée du saint, les disciples et les fidèles sont invités par les gendarmes à quitter les lieux. Les processions des Aïssâwa se déroulent toute la nuit et jusqu'au petit matin. En 2003, j'ai comptabilisé la visite de 9 tâ if $a$-s lors du deuxième jour du mussem.

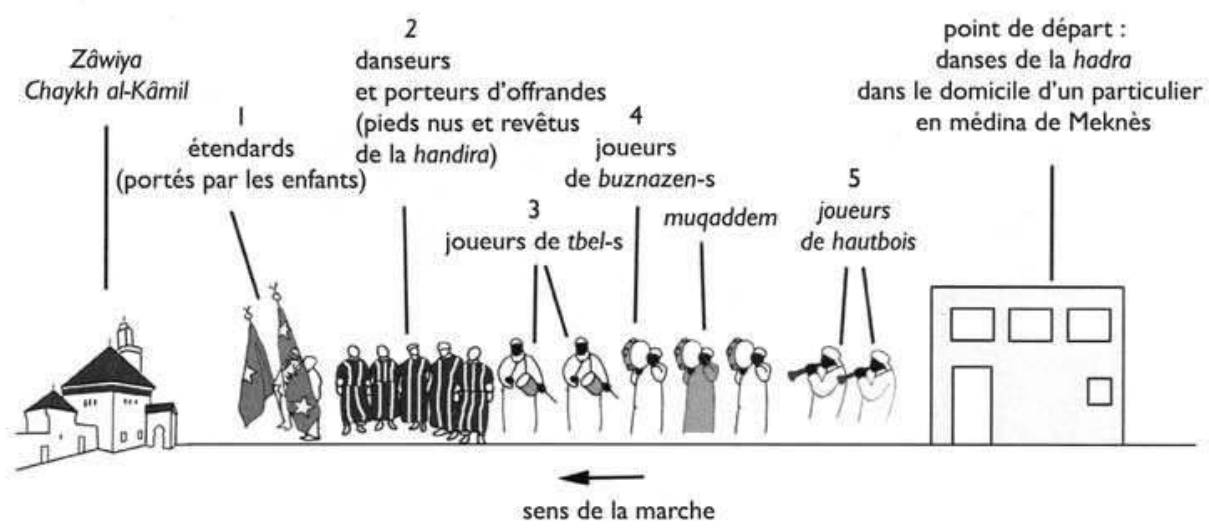

Fig. 3 Dessin de la visite des Aïssâwa le soir du $2^{e}$ jour

- Le troisième et dernier jour du mussem voit la venue de la tâ ifa du Palais royal de Rabat qui se charge d'apporter l'offrande (al-ziyâra) du roi au sanctuaire, constituée d'un taureau (appelé «le cadeau du roi ", al-hadiyya malakiyya) et d'une importante somme d'argent (al-hîba malakiyya). Le défilé de ce dernier jour est tout à fait protocolaire : vers 16 heures, la tâ 'ifa, entourée de personnalités officielles (hauts fonctionnaires, commissaire et préfet), commence par jouer le Rabbânî dans l'enceinte du Palais royal derrière la porte de bab al-Mansûr. Les spectateurs, attirés par la musique, se massent rapidement sur la place Moulay Ismail pour assister à l'ouverture des portes du Palais royal d'où sort la tâ `ifa entourée des militaires de la 
Fig. 4 Plan de l'aménagement de la zâwiya-mère

cimetière

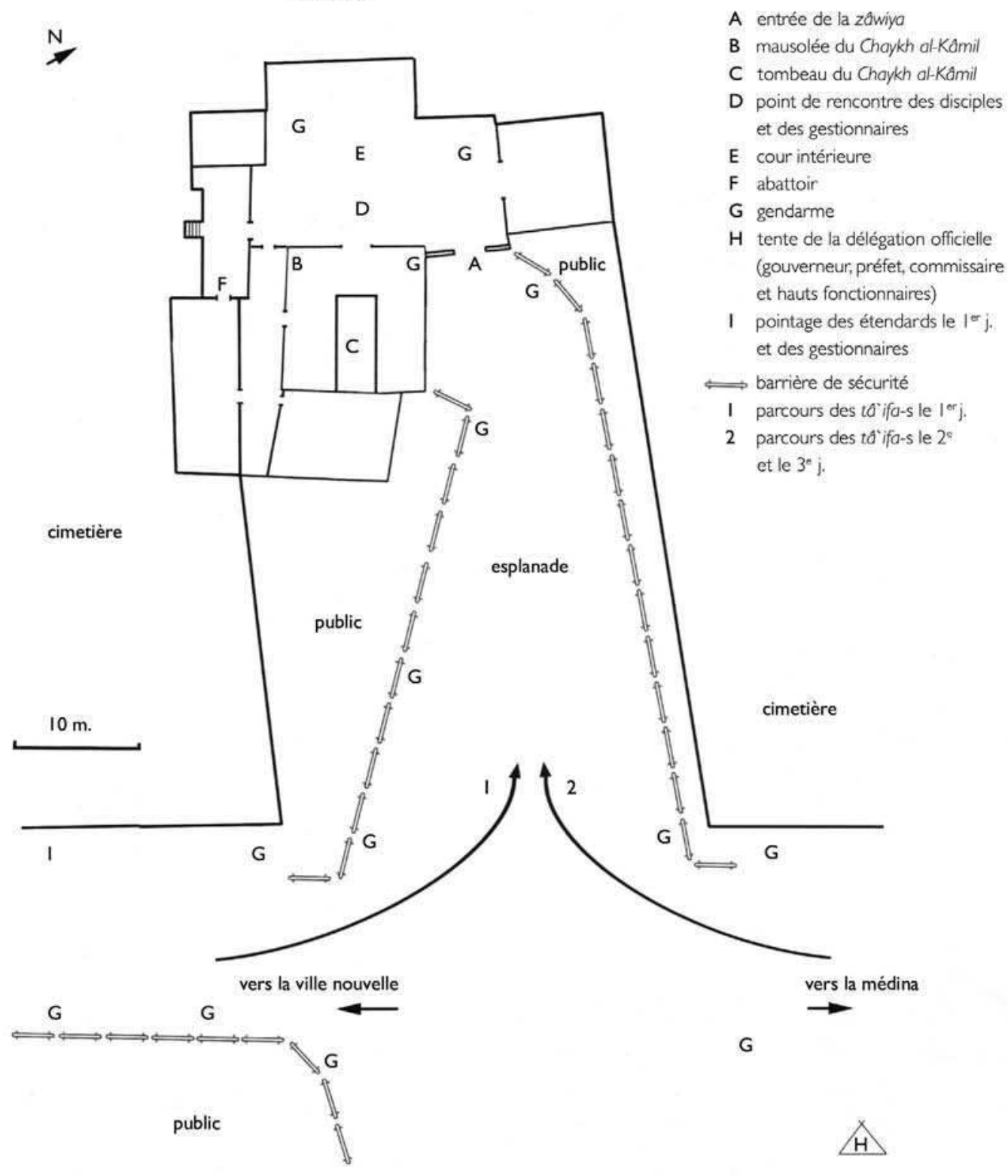


immédiatement reçus par les gestionnaires de la zâwiya. Le taureau est sacrifié par l'un des descendants du Chaykh al-Kâmil dans la cour intérieure. Le mausolée est ouvert au public mais reste étroitement surveillé par plusieurs dizaines de militaires et de gendarmes qui n'hésitent pas à utiliser la force pour écarter les éventuels perturbateurs. Les fidèles se pressent dans la zâwiya pendant que la tâ ifa du Palais royal quitte les lieux. À la tombée de la nuit, le muqaddem des lieux organise et dirige une séance de litanies collectives a cappella qui se tient jusqu'au matin et mène plusieurs participants à l'extase. C'est avec cette soirée que se termine le mussem. Une semaine plus tard, la septième nuit du mawlid (qui correspond à l'attribution du nom au Prophète), les gestionnaires me disent qu'ils organisent, dans le mausolée de leur ancêtre, une veillée spirituelle au cours de laquelle les disciples chantent des cantiques sans accompagnement instrumental (samâ’) et récitent des poésies de la Burda et de la Hamziyya $^{13}$. Contraint de rentrer en France, je n'ai pas pu assister à cette réunion confrérique.

\section{Auprès du public pèlerin}

Le temps du mussem, Meknès devient une ville de pèlerinage où les processions sont, nous l'avons vu, localisées dans l'espace (le parcours se déploie de l'intérieur de la médina à la porte de $b a b$ al-jdîd où se trouve la zâwiya) et dans le temps (sur trois jours). Il convient cependant de différencier plusieurs catégories de public pèlerin qui le fréquentent, sachant que par pèlerin, j'entends toute personne qui visite la zone des festivités à cette occasion. Qui sont les pèlerins? Peut-on en dresser un profil type? On observe une grande variété en termes d'origine régionale et de classe sociale et le pèlerinage ne revêt pas la même signification pour tous les individus. Tout d'abord, nous trouvons des pèlerins qui manifestent le besoin ponctuel d'une médiation symbolique avec le tombeau du saint. Leurs visites sont généralement répétées et ne prennent pas fin le troisième jour du mussem mais se déroulent de façon routinière tout au long de l'année et à travers le réseau de saints marocains. Une autre catégorie de pèlerins est constituée d'individus qui sont liés plus formellement au Chaykh al-Kâmil et à la fréquentation de son sanctuaire. Ces personnes ont fait allégeance à un représentant reconnu de la confrérie (un muqaddem) et organisent chaque année une cérémonie domestique suivie d'une procession nocturne dans le cadre du pèlerinage. Une troisième catégorie rassemble les disciples (fuqarâ') qui ont fait vœu, pour une durée

13. Al-Hamziyya: recueil de poèmes que je n'ai pas pu identifier. 
déterminée ou non, de consacrer leur vie à la confrérie. Nous trouvons d'une part des disciples isolés, qui vivent leur pratique du divin indépendamment des tâ'ifa-s, et, d'autre part, des adeptes constituant l'effectif des $t \hat{a}$ if $a$-s, qu’ils soient originaires des régions rurales ou des centres urbains. S'ajoutent les commerçants qui investissent la sphère publique pour un négoce plus ou moins formel (vente de rafraîchissements, confiseries, sandwichs, ballons pour les enfants, disques et cassettes, fruits, légumes) et enfin les représentants de l'État (préfet, commissaire, hauts fonctionnaires et forces de l'ordre). Le pèlerinage attire de nombreux autres pèlerins. On citera pour mémoire les principaux groupes. Les hanayat, ces femmes qui réalisent des tatouages au henné, et les mendiants, souvent des musiciens, qui cherchent à se faire passer pour dépositaires du charisme du chaykh, sont nombreux. Ces groupes haranguent les passants en tentant de leur vendre une part de la baraka contre quelques pièces. Mon propos ici est de définir la signification du mussem pour quelques-uns de ces individus. À ce niveau d'analyse, je distinguerai deux types d'attitudes : l'adhésion ou l'opposition au mussem.

\section{L'approbation du mussem}

L'acceptation du mussem se manifeste dans les témoignages recueillis in situ et le comportement que les pèlerins adoptent le temps de la manifestation. Ce sont tout d'abord les disciples venus des régions rurales qui m’ont témoigné la plus grande adhésion au pèlerinage. L'état de pèlerin nécessite une rupture avec leur milieu social mais pas avec leur milieu familial. Pour beaucoup, le mussem apparaît à la fois comme l'occasion de se retrouver parmi une communauté de croyants et de voyager en famille, à travers le Maroc, sur la route des sanctuaires des saints locaux. C'est ce que dit Haj Y., 63 ans, retraité et muqaddem d'une tâ ifa à Mechraâ Bel Ksiri, près de Sîdî Kacem :

"Le mussem du Chaykh al-Kâmil nous permet de nous ressourcer et de nous retrouver. C'est ici que les Aïssâwî se retrouvent pour célébrer l'anniversaire du Prophète, car alHâdî ben Aïsâ est l'un de ses descendants. C'est lui-même qui a conseillé à ses premiers disciples de se rendre une fois par an à la zawiya pendant le mawlid [...]. On est venu avec toute la famille par le train, on reste juste une semaine. Demain on visite le chaykh, ensuite on va à Moulay Idriss Zerhoun et à Sî̀î 'Alî pour le mussem des Hamadcha ".

Pour les commerçants ambulants qui envahissent les rues tout autour du sanctuaire, le mussem est vu avant tout comme le lieu et le moment idéals de réaliser de grandes marges de bénéfices. Voici le récit de Y., 26 ans, vendeur informel de téléphones portables: 
«Le mussem c'est un moment particulier pour nous, parce que d'habitude la police nous chasse lorsqu'elle nous aperçoit. Mais là on peut vendre sans crainte, il y a un relâchement de ce côté. Il y a beaucoup de monde et le commerce marche très bien, grâce à Dieu. Il faudrait qu'il y ait des mussem-s tous les jours!»

Ce sont surtout les femmes qui m'ont fait part d'un grand intérêt aux pratiques rituelles des Aïssâwa. Certaines voient le mussem comme un spectacle de divertissement qui est aussi l'occasion de mieux connaître la culture du pays. C'est ce que m'explique madame R., 42 ans, infirmière :

"J'habite à Meknès et c'est la première fois que je viens au mussem. J'ai souvent entendu parler des Aïssâwa et je voulais voir de mes yeux si toutes ces histoires de transe sont vraies. Ça fait partie de notre culture et c'est dommage de ne pas voir ça au moins une fois [...]. J'ai des cassettes des Aïssâwa à la maison, j'aime beaucoup leur musique. J'espère qu'ils vont mettre l'ambiance ».

Pour d'autres, c'est d'abord l'aspect religieux qui motive leurs visites de la zâwiya. Des pèlerins intègrent le mussem du Chaykh al-Kâmil à l'intérieur d'un circuit qui les conduit d'un lieu saint à l'autre à travers le pays. Écoutons madame T., 45 ans, sans emploi :

"Nous avons l'habitude de visiter plusieurs zâwiya-s les jours des mussem-s. Après Meknès, on va à Sîdî 'Alî et ensuite à Moulay Brahim. C'est un trajet que nous faisons presque chaque année avec mon mari et les enfants".

Les requêtes des pèlerins évoluent avec la modernisation de la société : réussir un examen, trouver un emploi ou gagner de l'argent. Mais les suppliques désespérées restent toujours présentes lorsqu'il s'agit de demander la guérison d'une infirmité physique, de désirer une grossesse ou de trouver un conjoint. Pour monsieur Y., chauffeur de taxi à Meknès, le mussem est l'occasion de renouer le pacte qui lie sa famille au Chaykh alKâmil. Sa femme organise tous les ans une cérémonie domestique et ils participent en famille à la procession jusqu'au sanctuaire avec les Aïssâwa :

"Il y a trois ans, ma femme est venue toutes les semaines au Chaykh al-Kâmil, parce que les médecins la disaient stérile. Depuis nous avons eu un enfant, grâce la baraka $\mathrm{du}$ chaykh. C'est la raison pour laquelle elle organise une lîla chaque année, c'est notre remerciement".

L'adhésion du public pèlerin au mussem revêt donc plusieurs formes. Le pèlerinage répond à la fois à une pratique religieuse, à une recherche d'expressions culturelles et festives, à une volonté de vivre un voyage touristique et familial et apparaît comme une opportunité économique pour les commerçants ambulants. Intéressons-nous maintenant à l'opposition que certains individus manifestent. 
L'opposition au mussem est exprimée d'une part dans les actes et récits des spectateurs et, d'autre part, dans les témoignages des Aïssâwî interrogés. Des jeunes hommes investissent le site pour tenter d'empêcher les processions et de ridiculiser les pratiques rituelles des disciples. Leurs actes et leurs paroles, exprimés ouvertement, sont d'une grande violence et entraînent des altercations avec les disciples et les forces de l'ordre. Le premier jour du mussem, lors d'une hadra célébrée le long du mur du cimetière par un groupe de disciples, un homme s'est avancé dans le cercle des danseurs et a frappé le muqaddem au visage. Son geste a immédiatement provoqué une rixe générale. Les gendarmes sont arrivés très rapidement et ont menotté l'agresseur avant de l'emmener. Tout en tentant de se débattre, celui-ci a eu néanmoins le temps de clamer haut et fort: «Pays de merde, je les déteste, eux et leur zâwiya!»Un gendarme s'est saisi ensuite d'un porte-voix et s'est adressé au public en ces termes:

"Ce jour est celui du mussem des Aïssâwa. Ces disciples sont les hôtes de la zâwiya, ils sont les invités et ont le droit de pratiquer leurs croyances. Ceux qui ne les supportent pas peuvent évidement quitter les lieux, mais ils ne doivent en aucun cas les violenter ».

J'ai ainsi assisté, sur les trois jours du mussem, à cinq échauffourées de ce type. Des tensions apparaissent aussi lorsque les disciples ruraux, en état de transe, réalisent le premier jour la course de la 'ada et les danses animalières sur l'esplanade de la zâwiya. Là, des groupes d'adolescents les insultent en usant de termes obscènes. D'autres, munis de pierres et de bouteilles, jettent leurs projectiles en direction des danseurs, agressant les dévots qui stoppent leurs processions et s'adressent à eux pour tenter de calmer la situation. Les gendarmes réprimandent toujours très sévèrement les provocateurs, parfois par la force à l'aide de matraques, d'autres fois par des tirs de revolvers pointés vers le ciel. Si les disciples ont la réputation d'être incontrôlables et violents lors de leurs transes, les gendarmes constatent qu'ils sont plutôt la cible des personnes hostiles à ces pratiques. Écoutons M., 32 ans, gendarme à Meknès et chargé de réguler l'entrée de la zâwiya:

«Les disciples ne sont une menace pour personne. Par contre le public est un danger pour eux. Sans les barrières de sécurité et tous les gendarmes, les Aïssâwî finiraient lynchés, tu peux en être sûr. On a un très gros travail pour maintenir la sécurité des fidèles ici. Il y a beaucoup de jeunes qui viennent pour se moquer d'eux et les agresser, sans parler des voleurs ».

La forte présence policière sur les lieux entraîne de nombreux fidèles interrogés à en déduire que les mussem-s et les lieux saints, soupçonnés de favoriser la débauche et les mauvaises rencontres, sont volontairement maintenus par l'État pour dominer la population. Voici, à ce propos, l'avis de J., 
26 ans, vendeur de pâtisseries sur le site de la zâwiya, qui reproche aussi que le charisme du chaykh éclipse en ces jours celui du Prophète:

"Je n'aime pas du tout ces fêtes, le mawlid c'est la fête de la naissance du Prophète, et lui-même jeûnait ce jour-là. Ici l'islam est éclipsé par "les festivités dues à Chaykh alKâmil”. Ce mussem c'est la résurgence du passé qui laisse tous ces gens dans l'ignorance absolue. À l'heure actuelle tout le monde regarde vers l'avenir, et nous on regarde toujours vers l'arrière. Des gens au Maroc ont intérêt à ce que les autres gens "pourrissent" dans le passé, ils les aident même avec leurs encouragements et leurs préparatifs. Le mussem de Chaykh al-Kâmil absorbe, dépasse et annule même la fête de l'anniversaire de notre Prophète. Ici toutes sortes de débauches sont pratiquées et célébrées, avec tous les encouragements des responsables politiques... Devine pourquoi, c'est facile à comprendre... Malgré tout, ces festivités rapportent un peu à Meknès mais elles sont la source de beaucoup de crimes et délits".

L'opposition au mussem recouvre donc plusieurs formes. D'un coté, certains individus viennent manifester leur désapprobation aux pratiques rituelles par des actes de violence sur les disciples lors des processions. D'un autre côté, les entretiens menés auprès de quelques commerçants ambulants, qui tirent néanmoins profit de cette manifestation, font apparaître là aussi un rejet de ces pratiques qu'ils considèrent comme rétrogrades et éloignées de l'islam sunnite.

En comparant mes données avec celles des chercheurs antérieurs sur le mussem de Meknès (Brunel 1926; Boncourt 1979; Lahlou 1986), je constate que le déroulement du mussem n'est pas immuable et connaît des transformations apparues au fil du temps. De fait, ma description vaut pour ce qu'elle est et n'ambitionne en aucun cas la détermination d'un modèle invariable. Cependant, force est de constater que cette tradition est aujourd'hui en perte de vitesse.

\section{Une tradition sur le déclin}

Cette étude du mussem de Meknès en ce début du XXI siècle m’oblige à constater son déclin inévitable qui se manifeste selon trois axes: une rupture symbolique entre la zâwiya et les disciples, le rejet du ludique et une non-promotion par les autorités publiques. Décrivons ces faits.

\section{Une rupture symbolique entre la zâwiya et les disciples marocains}

Mon enquête fait apparaître une rupture symbolique entre la zâwiya et les disciples marocains. Cela se manifeste par une nette diminution du nombre de groupes Aïssâwa et de visiteurs depuis 1986. Dans sa thèse Abdelati Lahlou indique la visite de 40 tâ if $a$-s venues des régions rurales en 1984 le premier jour du mussem (1986: 243) (alors que Brunel et Boncourt ne fournissent aucune donnée quantitative à ce sujet). De mon 
côté, j'ai comptabilisé 12 tâ if $a$-s le premier jour, 7 le deuxième jour et une seule le troisième jour. Ces chiffres indiquent clairement une baisse du taux de participation des disciples à ce mussem. Quant au public, il est très difficile d'avoir des chiffres précis. Lahlou indique qu'en 1968, le mussem attirait plus de 100000 personnes sur les trois jours (Ibid. : 240). Les représentants des forces de l'ordre interrogés en 2003 estiment à 30000 le nombre total de visiteurs sur les trois jours, le pic étant atteint le soir du deuxième jour avec 17000 personnes. Pour résumer, voici un tableau récapitulatif de la présence des groupes de disciples et des visiteurs :

\begin{tabular}{|c|c|c|c|}
\hline & $\mathrm{I}^{\mathrm{er}}$ jour & $2^{\mathrm{e}}$ jour & $3^{e}$ jour \\
\hline $\begin{array}{c}\text { Nombre de groupes Aïssâva } \\
\text { en } 1986 \text { selon Lahlou }\end{array}$ & 40 & NC & NC \\
\hline $\begin{array}{l}\text { Nombre de groupes Aïssâva } \\
\text { en } 2003 \text { selon mon enquête }\end{array}$ & 12 & 7 & 1 \\
\hline $\begin{array}{l}\text { Nombre de visiteurs } \\
\text { en } 1986 \text { selon Lahlou }\end{array}$ & \multicolumn{3}{|c|}{100000 environ } \\
\hline $\begin{array}{c}\text { Nombre de visiteurs } \\
\text { en } 2003 \text { selon mon enquête }\end{array}$ & \multicolumn{3}{|c|}{30000 environ } \\
\hline
\end{tabular}

Pour saisir ce phénomène, il faut comprendre que la célébration du mussem est actuellement fortement décriée par les muqaddem-s Aïssâwî interrogés. Ce fait découle des controverses internes actuellement dans la confrérie (Nabti 2007 : 281-300). Lors des entretiens menés auprès de 127 disciples Aïssâwî de Fès et Meknès, 93\% d'entre eux ont rejeté la notion d'allégeance au Chaykh al-Kâmil et à ses descendants biologiques (Ibid.). D’une part, le culte des saints est considéré par eux comme une pratique contraire à l'islam sunnite, et, d'autre part, les gestionnaires actuels de la zâwiya - qu'ils accusent d'être intéressés uniquement par l'économie engendrée par cette pratique - sont jugés inaptes à la direction spirituelle de l'ordre religieux. Le récit du muqaddem Haj Saïd El Guissy me fait comprendre, avec humour, les relations qu'il vit avec les gestionnaires de la zâwiya-mère :

«La dernière fois que je suis allé au mussem c’était il y a plus de dix ans. J’y suis allé avec mon groupe plus une centaine de personnes, le cortège de la ziyâra [l'offrande, $n d r$ a mis six heures pour arriver dans la zâwiya. Une fois dans le mausolée du Chaykh alKâmil, j'ai mis mille dirhams en liquide dans la rbia [la caisse pour les dons, $n d r$ ] et j'ai 
donné quatre mille dans une enveloppe au mezwâr [le surintendant, $n d r$ ]. Il a ajouté "ce n'est pas assez, je veux le double l'année prochaine”. J'ai répondu qu'il y a quand même cinq mille dirhams au total, et il m'a dit "toi tu es riche, tu fais beaucoup de soirées, tu fais des concerts à l'étranger et tu enregistres des disques". Alors je lui ai répondu "Hé! Je ne suis pas Michael Jackson!" Depuis cette date, la zâwiya et le mussem c'est fini pour moi. Ça sert à rien d'y aller, "les fils du chaykh" n’ont pas la tarîqa dans le cœur ».

Le muqaddem Haj Saïd Berrada refuse lui aussi de se rendre au pèlerinage annuel. Pour expliquer sa position, il m'a raconté une série d'anecdotes censées me dissuader d'y assister. Le muqaddem-muqaddmin Haj Azedine Bettahi me confirme que les Aïssâwa de Fès et de Meknès ne se rendent plus au mussem depuis une dizaine d'années. Les plus assidus, selon lui, seraient les Aïssâwa de Casablanca et de Salé. Du côté des Aïssâwî interrogés, le mussem catalyse toutes les tensions qui existent entre eux et la hiérarchie de l'ordre. Ils refusent ainsi d'entretenir le lien symbolique par le biais des offrandes rituelles et l'allégeance aux descendants du chaykh est clairement écartée. Cependant, ils ne rejettent pas ce modèle rituel et participent à d'autres mussem-s, plus particulièrement ceux de Moulay Idriss $1^{\text {er }}$ (sur le mont Zerhoun) et Moulay Idriss 2e (Fès).

À part cette rupture symbolique, j'ai constaté auprès des fidèles et des disciples l'absence d'un personnage-animal très particulier qui a pour fonction d'exprimer la part festive du pèlerinage. Ce fait annonce-t-il un phénomène de rejet du divertissement?

\section{Le rejet du ludique}

De tous les personnages-animaux présents dans la confrérie des Aïssâwa, le loup ( $a l-d \hat{b} b$ ), par ses caractéristiques comiques, est celui qui a intéressé tout particulièrement André Boncourt qui lui a consacré un article: "Le personnage de Chacal chez les 'Isawa du Maroc » (1979). Boncourt traduit le mot dîb par "chacal », mais pour moi, et les Aïssâwî francophones interrogés me le confirment par ailleurs, le dîb est le loup, le chacal étant le ibn'awa. Selon les écrits de Boncourt, le loup est le moins valeureux des personnages-animaux et il est le seul à porter un déguisement burlesque composé de grosses lunettes de soleil, un chapeau berbère multicolore sur lequel sont fixées des ampoules électriques, une sacoche dissimulant un combiné téléphonique, un cahier d'écolier, une carotte et un bâton. Le loup est seulement présent lors des processions du mussem où il tient le rôle de bouffon. Il amuse le public en parodiant le comportement du muqaddem et en tentant de dérober le contenu des poches des spectateurs. En se servant de sa carotte pour écrire sur un cahier d'écolier et par une élocution inintelligible, il singe aussi les lettrés musulmans (tâleb-s). Au beau milieu des danses de la hadra, il fait mine de téléphoner au Chaykh 
al-Kâmil en sortant le combiné de sa sacoche. Son comportement comique fait rire aux éclats l'assistance. Les parodies qui caractérisent certains rituels maghrébins sont analysées par Sossie Andezian (2001: 157-158) avec la notion d' "inversion symbolique" (symbolic inversion) empruntée à l'anthropologue Barbara A. Babcock. Cette "inversion symbolique" qualifie tout type d'expression corporelle excessive qui contredit ou présente une alternative à diverses valeurs et normes culturelles communes et collectivement admises, qu'elles soient à la fois politiques, sociales, linguistiques et artistiques. L'aspect récréatif du loup ne doit pas occulter qu'avant tout, c'est d'eux-mêmes et de leur place dans la société marocaine que les Aïssâwa se moquent, et cela n'échappe pas à Andezian qui souligne, d'une façon plus générale:

«S'agit-il pour autant d'une contestation, d'une perversion, d'une subversion de l'ordre établi ? En apparence oui, mais il reste évident pour tout le monde [...] qu'il s'agit d'un "jeu" [...]. [Cela] se présente comme une lecture [...] de leur expérience de la société $[\ldots]$ et des règles qui régissent les rapports sociaux entre différentes catégories de personnes et de groupes [...]. Mais c'est une lecture critique, présentée avec beaucoup d'humour. L'importance de toute chose est relativisée, seule leur capacité à faire rire donnant encore sens aux mots et aux gestes" (Ibid.).

Lors des mussem-s je n'ai jamais vu de loup. Aurait-il totalement disparu? Les Aïssâwî interrogés affirment que les anciennes pratiques telles que la frissa et le comportement burlesque du loup «ne marchent pas avec l'islam ». Par le rejet qu'ils manifestent face aux anciens rites, ils ambitionnent de devenir, prétendent-ils, de "meilleurs musulmans " que ne le furent leurs ancêtres. Par exemple, pour le muqaddem Haj Saïd Berrada, le loup fait définitivement partie du passé, et il s'en réjouit. C'est lui qui, le premier, me montra un loup sur une vidéo familiale filmée lors du mussem de Meknès dans les années 1980. Pour lui, tout cela n'est rien d'autre que du spectacle. Le loup est jugé avec mépris, sans lien avec l'islam et donc sans intérêt :

"Voila le loup... C'est n’importe quoi... C'est quoi ça ? C'est quoi le rapport avec l'islam ? C'est du théâtre et rien d'autre. Tu vois les anciens Aïssâwî, ils ne connaissaient rien, ils faisaient n'importe quoi..."

Pour le muqaddem-muqaddmin Haj Azedine Bettahi, le loup avait une valeur liée à la seule fonction qu'il lui attribue, celle de faire remarquer la tâ ifa lors des mussem-s :

"Avant, le loup était seulement présent dans les mussem-s. Il servait à attirer l'attention du public et à montrer que les Aïssâwa sont là. Mais c'est terminé maintenant, plus personne ne fait le loup. L'évolution de la société et des mentalités fait qu'il a disparu des tâ $` i f a-s$ modernes". 
Ainsi le mussem est un événement variable par son déroulement qui reste lié à des paramètres extérieurs plus larges tels que les intempéries et les événements politiques. Les pratiques rituelles ne sont pas reproduites à l'identique chaque année et se modifient selon la situation sociale et politique. N'oublions pas que les Aïssâwa de ce début de XXI ${ }^{e}$ siècle sont en prise avec les évolutions politiques et religieuses du Maroc contemporain dans un contexte géopolitique particulièrement sensible. Dans tous les domaines de la société, une vision conservatrice de l'islam est diffusée par les 'ulamâ ' conservateurs, parallèlement aux islamistes qui s'efforcent d'imposer une vision rigoriste des textes sacrés. Il n'est donc pas étonnant de constater ces mêmes discours chez certains Aïssâwî interrogés qui manifestent une conscience musulmane conservatrice. Leur rejet des anciennes pratiques liées au mysticisme provoque actuellement la disparition, peutêtre seulement momentanée, du personnage burlesque du loup qui se manifestait pendant le mussem.

Nous arrivons à présent sur le dernier fait exprimant selon moi le déclin de ce mussem : il s'agit de sa non-promotion par les autorités publiques.

\section{La non-promotion par les autorités publiques : un pèlerinage "déshonorant"?}

Il est significatif de noter que les étrangers intéressés par les mussem-s seront immanquablement orientés par les offices de tourisme officiels vers huit mussem-s particulièrement soutenus par l'État dans le cadre de plans de développement touristique. Des agences de voyage locales organisent des excursions pour permettre aux touristes d'y assister. Il s'agit du mussem des roses (près de Ouarzazate, dans le sud du pays), du mussem des Touaregs (à Tan Tan aux portes du Sahara), du mussem des fiançailles des Aït Haddidou (dans l'Atlas), du mussem des fiançailles d'Imilchil (dans le haut Atlas), du mussem de Moulay 'Abdallah Amrar (à Tit, site balnéaire sur l'océan Atlantique), du mussem de Moulay 'Abdallah (à Jadida sur la côte atlantique) et des mussem-s de Moulay Idriss Al-Azhar à Fès ${ }^{14}$ et celui de Moulay Idriss Zerhoun ${ }^{15}$. Malgré le millier (cf. Berriane 1993 : 30) de mussem-s célébrés chaque année au Maroc, seuls ces huit sont vantés dans les dépliants touristiques marocains comme des «festivités traditionnelles typiques " se déroulant dans des sites d'une grande beauté. D’un autre

14. Le muqaddem-muqaddmin Haj Bettahi m'a accueilli dans sa tâ ifa les jours du mussem de Moulay Idriss à Fès en septembre 2005. J'ai assisté, d'une part, à sa préparation dans les coulisses de la préfecture et, d'autre part, aux processions rituelles. J'espère pouvoir publier les résultats de cette recherche.

15. En août 2002, en tant que membre temporaire de la tâ’ ifa du muqaddem Haj Berrada, j’ai participé aux processions du mussem de Moulay Idriss Zerhoun jusqu'à l'intérieur du sanctuaire du fondateur de la première dynastie musulmane marocain. 
côté, les mussem-s considérés comme ayant une renommée nationale par les Marocains interrogés lors de mon enquête sont celui de Meknès, de Sîdî 'Ali ben Hamdûch (dans le massif montagneux du Zerhoun) ${ }^{16}$, de Moulay Idriss à Fès et de Moulay Idriss Zerhoun. Seuls les deux derniers sont retenus par les organismes touristiques du pays. Pourquoi ces derniers ne font-ils pas la promotion des mussem-s plébiscités par les Marocains (qui sont par ailleurs promotionnés par les guides touristiques français comme des événements caractéristiques de la vie religieuse Marocaine) ${ }^{17}$ ?

Je pense que les effets spectaculaires présents lors de certains mussem-s tels que celui de Meknès ne reflètent pas, pour l'État, l'image du Maroc authentique, malgré le fait que les pratiques rituelles liées au mysticisme sont la réalité d'un grand nombre de Marocains. La gestion de ce type de mussem-s par les autorités du pays dévoile un phénomène de honte de l'intimité, les autorités ne semblent pas avoir grand intérêt à présenter ces rituels extatiques aux visiteurs étrangers. La non-reconnaissance de ces faits critiques, qui dévoilent l'image d'un peuple "barbare», devient des "secrets inavouables", c'est-à-dire "incompatibles avec l'image que le représentant de l'autorité s'efforce de maintenir en public» (Goffman 1979 : 37). Interdire ces manifestations apparaît comme impossible, car trop de personnes sont engagées dans ces pratiques. Mais l'État montre qu'il maîtrise ces formes religieuses et qu'il a prise sur elles par son intervention, d'une part, dans la nomination des membres de la hiérarchie confrérique, et, d'autre part, dans le déroulement des festivités.

Université de Montréal Chaire de recherche du Canada, islam, pluralisme et globalisation mehdi.nabti@umontreal.ca

MOTS-CLÉS/KEYWORDS : soufisme/sufism - islam - Aïssâwa - Maroc/Morocco - Meknès mussem - pèlerinage/pilgrimage.

16. J'ai participé au mussem de Sîdî 'Alî ben Hamdûch avec la tâ ifa du muqaddem Hamdûchî 'Abderrahim Amrani Marrakchi en mai 2005. J'ai pu être hébergé pendant trois jours au sein de la zâwiya du saint fondateur des Hamadcha et assister et filmer quatre cérémonies confrériques. 17. De nombreux guides touristiques français font la promotion du mussem du Chaykh al-Kâmil. Voir par exemple Maroc, Paris, Michelin Éditions des voyages, 2001 ("Le Guide Vert») : 270, et Maroc, Paris, Gallimard, 2000 ( Guide Gallimard») : 240. 
BIBLIOGRAPHIE

Aissawi Al-Chaykh Al-Kamil, Abdelatif

2004 Sîdî Muhammad ben Aïssa. Tarîqa wa zâwiya istimrariyya (= Mầtre Muhammad ben Ä̈ssâ. Tarîqa, zâwiya et continuité). Rabat, Mârîf.

Al Malhouni, Abderrahim

2003 Adwae 'ala tasawwuf bî al-maghrib: tarîqa al-Aïsssâwiyya mamuzâjan. Min khilâl chir al-malhûn, al-hikâya cha'biya sufiya, almuradadât chafâhiya, 'awayd turuqiyyin (= Lumières sur le soufisme au Maroc. La tarîqa Aïssâwiyya pour exemple). Rabat, Ministère de la Culture éd.

\section{Andezian, Sossie}

2001 Expériences du divin dans l'Algérie contemporaine. Adeptes des saints de la région de Tlemcen. Paris, CNRS éd.

\section{Berriane, Mohamed}

1992 Tourisme national et migrations de loisir au Maroc (étude géographique). Rabat, Publications de la faculté des lettres et des sciences humaines, université Mohammed V. 1993 "Le moussem au Maroc: tradition et changements ", Géographie et Cultures 7 : 27-51.

\section{Boncourt, André}

1979 "Le personnage de Chacal chez les "Isawa du Maroc ", Revue des Africanistes 48 : 31-61.

1980 Rituel et musique chez les 'Isawa citadins du Maroc. Strasbourg, thèse de doctorat de $3^{\text {e }}$ cycle, Institut d'anthropologie et d'ethnologie.

Bonte, Pierre, Anne-Marie Brisebarre \& Atlan Gokalp, eds

1999 Sacrifices en Islam. Espaces et temps d'un rituel. Paris, CNRS éd.

Brunel, René

1926 Essai sur la confrérie religieuse des Aïssaouas au Maroc. Paris, P. Geuthner.
Chiffoleau, Sylvia \& Anna Madœuf

2005 Les Pèlerinages au Maghreb et au Moyen Orient. Espaces publics, espaces $d u$ public. Beyrouth, Ifpo.

\section{Crapanzano, Vincent}

2000 [1973] Les Hamadcha. Une étude d'ethnopsychiatrie marocaine. Trad. de l'anglais par O. Ralet. Paris, Institut d'édition Sanofi Synthélabo.

\section{Daoui, Mohamed}

s. d. Mawassim Chaykh al-kâmil bä̈ya al aws wa al yawn (= Le Moussem du Chaykh al-kâmil, entre hier et aujourd'hui). Ouvrage dactylographié en arabe. [Fourni par l'un des responsables de la confrérie en 2004.]

\section{Doutté, Edmond}

1900 Les Aïssâoua à Tlemcen. Châlons-surMarne, M. Frères (éd.).

1984 [1908] Magie et religion dans l'Afrique $d u$ Nord. Paris, J. Maisonneuve-P. Geuthner.

\section{Elabar, Fakhreddine}

1996 Transes, danses et musiques. Études d'anthropologie de l'islam d'un rituel soufi Aïssaoui dans la tariqa al Aïssaoua, Maknes, Maroc. Bordeaux, Université Bordeaux 2, mémoire de maîtrise.

2005 Musique, rituels et confrérie au Maroc. Les 'Issâwâ, les Hamâdcha et les Gnawa. Paris, École des hautes études en sciences sociales, thèse de doctorat d'anthropologie.

\section{Goffman, Erving}

1979 La Mise en scène de la vie quotidienne. Trad. de l'anglais par A. Accardo \& A. Kihm. Paris, Minuit.

Habermas, Jürgen

1978 L'Espace public. Archéologie de la publicité comme dimension constitutive de la société bourgeoise. Trad. de l'allemand par M. de Launay. Paris, Payot.

1992 "L'espace public, trente ans après ", Quaderni 18: 161-191. 


\section{Lahlou, Abdelati}

1986 Croyances et manifestations magicoreligieuses au Maroc: le cas de Meknès. Aixen-Provence, Université de Aix-Marseille, thèse de doctorat de troisième cycle.

\section{Madœuf, Anna}

1997 «Quand le temps révèle l'espace: les fêtes de Husayn et de Zaynab au Caire", Géographie et Cultures 21 : 71-92.

2001 «Les grands mûlids : des vieux quartiers du Caire aux territoires de l'islam ", La géographie en fête: 115-175.

\section{Massignon, Louis}

1908 « Les pèlerinages populaires à Badgad ", Revue du Monde Musulman 6 : 640-651.

1925 "Enquête sur les corporations musulmanes d'artisans et de commerçants au Maroc (1923-1924) d'après la circulaire résidentielle du 15 novembre 1923 ", Revue du Monde Musulman 58 : 167-168.

1949 «Géographie spirituelle et pèlerinage ", Dieu Vivant 14 : 45-72.

\section{Mayeur-Jaouen, Catherine}

1997a «Tombeau, mosquée et zâwiya : la polarité des lieux saints musulmans ", in André Vauchez, ed., Lieux sacrés, lieux de culte, sanctuaires. Approches terminologiques, méthodologiques, historiques et monographiques. Rome, École française de Rome: 133-147. 1997b «Lieux sacrés, lieux de culte, sanctuaires en islam ", in André Vauchez, ed., Lieux sacrés, lieux de culte, sanctuaires..., op. cit. : 149-170.

2004 Histoire d'un pèlerinage légendaire en islam. Le mouled de Tantâ du XIII siècle à nos jours. Paris, Aubier.

Nabti, Mehdi

2007 La Confrérie des Aissawa du Maroc en milieu urbain. Les pratiques rituelles et sociales du mysticisme contemporain. Paris, École des hautes études en sciences sociales, thèse de doctorat.

\section{Pâques, Viviana}

1971 «Les fêtes du Mwûlûd dans la région de Marrakech ", Journal de la Société des Africanistes 41 (1) : 133-145.

1991 La Religion des esclaves. Recherches sur la confrérie marocaine de Gnawa. Bergamo, Moretti \& Vitali.

\section{Reysoo, Fenneke}

1991 Pèlerinages au Maroc. Fête, politique et échange dans l'islam populaire. Paris, Éd. de la MsH/Neuchâtel, Éd. de l'Institut d'ethnologie.

\section{Saghir Janjar, Mohamed}

1984 Expérience du sacré chez la confrérie religieuse marocaine des Isawa. Contribution à l'étude de quelques aspects socio-culturels de la mystique musulmane. Paris, Université Paris 5 , thèse de doctorat. 
Mehdi Nabti, Le mussem de Meknès : le déclin d'une tradition spirituelle. - Les mussem-s sont des fêtes saisonnières, à la fois foires et pèlerinages célébrés aux environs du sanctuaire d'un saint personnage. Au Maroc, lors des festivités annuelles célébrant le jour de la naissance du prophète Muhammad, le Palais royal organise à Meknès le mussem du Chaykh al-Kâmil, censé représenter le pèlerinage des disciples de la confrérie soufie des Aïssâwa. Cet article décrit et analyse l'organisation et le fonctionnement de ce mussem dans le champ culturel et religieux du Maroc. Les données de l'auteur proviennent d'une enquête de terrain menée auprès du public pèlerin, des membres de la confrérie des Aïssâwa, des hauts responsables de l'ordre religieux et des autorités publiques. Par une approche socio-anthropologique et historique, le but est de saisir la signification et les enjeux de ce mussem dans la société marocaine contemporaine pour conclure sur son déclin depuis les années 1980.
Mehdi Nabti, The mussem of Meknès: The Decline of a Spiritual Tradition. - The mussem-s are seasonal festivals, both celebrated pilgrimages and fairs around the shrine of a holy man. In Morocco, during the annual festivities celebrating the day of birth of the prophet Muhammad, the government organizes in Meknès the mussem of the Shaykh alKamil, the pilgrimage for the members of the sufi brotherhood of Aïssâwa. This article describes and analyzes the organization and the functioning of this mussem in the field of culture and religion of Morocco. The Data of the author comes from an investigation conducted among the pilgrim audience, members of the brotherhood of Aïssâwa, senior officials of the religious order and public authorities. With a socio-anthropological and historical approach, the goal is to capture the meaning and the implications of this mussem in contemporary Moroccan society to conclude on the wane since the 80's. 